\title{
Consolidation of an Extinction Memory Depends on the Unconditioned Stimulus Magnitude Previously Experienced during Training
}

\author{
Nicola Stollhoff and Dorothea Eisenhardt \\ Freie Universität Berlin, Department of Biology/Chemistry/Pharmacy, Institute for Biology, Neurobiology, 14195 Berlin, Germany
}

Here, we examine the role of the magnitude of the unconditioned stimulus (US) during classical conditioning in consolidation processes after memory retrieval. We varied the US durations during training and we test the impact of these variations on consolidation after memory retrieval with one or two conditioned stimulus-only trials. We found that the consolidation of an extinction memory depends on US duration during training and ruled out the possibility that this effect is attributable to differences in satiation after conditioning. We conclude that consolidation of an extinction memory is triggered only when the duration of the US reaches a critical threshold. This demonstrates that memory consolidation cannot be regarded as an isolated process depending solely on training conditions. Instead, it depends on the animal's previous experience as well.

\section{Introduction}

Long-term memory (LTM) formation can be disturbed during a discrete time window after learning with protein synthesis inhibitors. It has been concluded that LTMs undergo a labile phase of memory fixation, called consolidation (Dudai, 2004). In classical conditioning, an animal learns that a previous neutral stimulus [conditioned stimulus (CS)] is associated with the unconditioned stimulus (US). Retrieving a consolidated memory about a CS-US association with a CS-only presentation results in two contrasting memories. One memory is formed about the fact that the CS is no longer predicted by the US (CS-no US association). This memory is termed extinction memory and undergoes consolidation (Quirk and Mueller, 2008). The second memory is formed about the previously learned CS-US association, a process named reconsolidation (Sara, 2000; Nader, 2003).

Several studies demonstrate that the duration and the frequency of the CS presentation during memory retrieval are crucial for one of these consolidation processes to occur (Eisenberg et al., 2003; Pedreira and Maldonado, 2003; Suzuki et al., 2004; Power et al., 2006; Lagasse et al., 2009). Thus, it is critical how long and how often the previously established CS-US association is activated during retrieval. Interestingly, it is unknown whether quality and magnitude of the stimuli that have been associated during conditioning play a role in memory consolidation after retrieval. Accordingly, we here aim toward elucidating this ques-

Received Jan. 29, 2009; revised June 30, 2009; accepted June 30, 2009.

This study was supported by the Volkswagenstiftung (1/77378) and a position for D.E. and N.S. from the Deutsche Forschungsgemeinschaft (EI 512/1-2). We thank Randolf Menzel for critical reading of a previous version of this manuscript, and Rodrigo De Marco and Mariana Gil for fruitful discussions.

Correspondence should be addressed to Dorothea Eisenhardt, Freie Universität Berlin, Department of Biology/ Chemistry/Pharmacy, Institute for Biology, Neurobiology, Königin-Luise-Strasse 28/30, 14195 Berlin, Germany. E-mail: theodora@zedat.fu-berlin.de.

D01:10.1523/JNEUROSCI.0495-09.2009

Copyright $\odot 2009$ Society for Neuroscience $\quad$ 0270-6474/09/299644-07\$15.00/0 tion by examining the role of the magnitude of the US for consolidation processes after memory retrieval.

We studied this question in an appetitive pavlovian learning paradigm in the honeybee (Apis mellifera). Hungry honeybees react with a proboscis extension response (PER) when their antennae are touched with sucrose solution (US). They learn the association between a previously neutral odor (CS) and the US and form a memory about it (Menzel, 1999). Retrieving a consolidated olfactory memory results in either the reconsolidation phenomenon or the consolidation of an extinction memory, depending on the number of retrieval trials: five retrieval trials lead to the reconsolidation phenomenon, whereas two retrieval trials result in the consolidation of an extinction memory $24 \mathrm{~h}$ later (Stollhoff et al., 2005). Here, we further elucidate the mechanisms that lead to memory consolidation after retrieval by asking about the role of the US magnitude. Previously, it has been demonstrated that honeybees are sensitive to one aspect of the US magnitude, the US duration, in a visual conditioning paradigm (Menzel, 1968). Thus, we vary the duration of the US presentation during conditioning and test the impact of this variation on memory consolidation after retrieval with one and two retrieval trials.

\section{Materials and Methods}

Behavioral procedure. The experiments were conducted in autumn 2004, autumn 2005, and summer 2007 in Berlin, Germany. The protocol was the same as described by Stollhoff et al. (2005).

In brief, foraging bees leaving the hive were caught in the afternoon, $1 \mathrm{~d}$ before the experiment started. They were immobilized by cooling, harnessed in small plastic tubes, and in the evening fed to satiation with sucrose $(1 \mathrm{M})$. During the rest of the experiment animals were fed with four droplets of sucrose $(\sim 15 \mu \mathrm{l})$ in the evening. Between experimental manipulations the bees were kept in a dark and humid box at room temperature.

Conditioning procedure. Acquisition consists of three odor pairings (CS) delivered through a $20 \mathrm{ml}$ syringe with sucrose $1.25 \mathrm{M}$ (US), with an 
intertrial interval (ITI) of $10 \mathrm{~min}$. An acquisition trial starts with a $10 \mathrm{~s}$ placement of the animal in front of an exhauster. Subsequently, the odor (clove oil) was presented for $5 \mathrm{~s}$. After $2 \mathrm{~s}$, the antennae were touched with a sucrose-moistened toothpick; then, the different experimental groups were allowed to lick the sucrose for 2,6 , or $10 \mathrm{~s}$. The conditioning schedule for the different groups is as follows: a group of animals received three trials with a constant US length of $2 \mathrm{~s}$ [short (S) group], a second group's trials had a constant US length of $10 \mathrm{~s}$ [long (L) group]. These two groups were run in parallel. A further experiment with three experimental groups was conducted later. One group received a constant US presentation of $6 \mathrm{~s}$ per trial [constant (const) group]. The second group received an upward US presentation schedule; i.e., in the first trial the US was presented for $2 \mathrm{~s}$, in the second trial for $6 \mathrm{~s}$, and in the last trial the US length was $10 \mathrm{~s}$ [upward (up) group]. The third group received the same schedule in a downward manner; in the first trial the US was presented for $10 \mathrm{~s}$, in the second for $6 \mathrm{~s}$, and in the third trial for $2 \mathrm{~s}$ [downward (down) group].

To equalize the time animals spent in front of the exhauster, bees with 2 or $6 \mathrm{~s}$ US duration were left for an additional 8 or $4 \mathrm{~s}$, respectively, after the US offset on the experimental side. A bee scored positive if it extended its proboscis between the onset of the CS and the presentation of the US.

Retention test/CS-only trials. CS-only trials were presented $24 \mathrm{~h}$ after acquisition and consisted of $5 \mathrm{~s} C S$ presentation without US presentation. If more than one CS trial was presented, the ITI was $10 \mathrm{~min}$. The final retention trial was performed $48 \mathrm{~h}$ after acquisition in the same way as CS-only trials.

Injection. Emetine (Eme; Fluka Chemie, catalog \#45160) was dissolved in PBS (in mM: $137 \mathrm{NaCl}, 2.7 \mathrm{KCl}, 10.1 \mathrm{Na}_{2} \mathrm{HPO}_{4}, 1.8 \mathrm{KH}_{2} \mathrm{PO}_{4}$, adjusted to $\mathrm{pH} 7.2)$. One microliter of emetine $(10 \mathrm{~mm})$ or saline was injected manually into the thorax using a calibrated glass capillary (Capilettor tips and sticks, Selzer GmbH, catalog \#224804 and \#224847). Injections were applied 30 min before the first CS-only trial.

Data analysis. Animals were included in the analysis that fulfilled three criteria: they survived the entire experiment, they showed the PER elicited by sucrose at the end of the experiment, and they did not show a spontaneous extension of the proboscis to the odor (CS) at the first CS-US pairing. For statistical analysis, differences were considered to be significant if $p<0.05$.

Within-group comparison. The McNemar $\chi^{2}$ test was used for the within-group comparison between the $\mathrm{CR}$ at the last extinction trial and the $\mathrm{CR}$ at the retention test.

Between-group comparison. The CR differences between differently treated groups were tested using the $G$ test for contingency tables ( $=\log$ likelihood ratio for contingency tables) (Zar, 1984).

\section{Results}

We here ask whether the magnitude of the US during conditioning has an impact on consolidation processes after retrieval. To this end, we vary the duration of the US and test the impact on memory consolidation after one and two retrieval trials.

Memory consolidation is defined as the time window during which the long-term form of a newly acquired memory can be blocked by inhibitors of protein or RNA synthesis (Dudai, 2002). Thus, to uncover memory consolidation after retrieval, we interfered with memory consolidation by application of emetine, an inhibitor of protein synthesis.

\section{Sensitivity of memory formation to protein synthesis inhibition $24 \mathrm{~h}$ after training does not depend on the US duration}

In a previous study we demonstrated that the consolidation process induced by training with a 4 s US presentation is not susceptible to protein synthesis inhibitors $24 \mathrm{~h}$ later (Stollhoff et al., 2005). In the present study a new conditioning protocol was used with a US lasting 2 or $10 \mathrm{~s}$, and it is therefore conceivable that the time course of consolidation may also change. The following experiment was conducted to test whether memory formation is

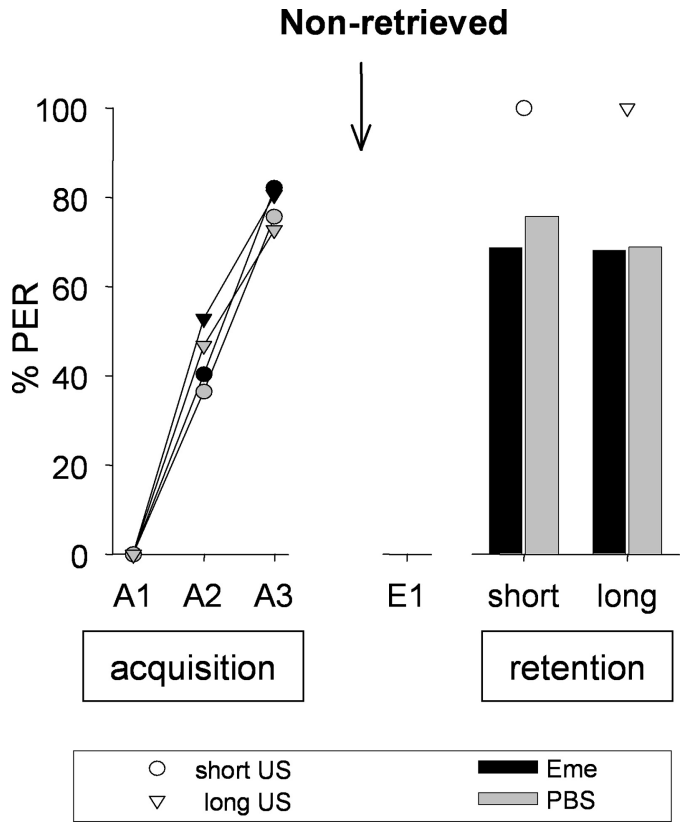

Figure 1. Sensitivity of memory formation to protein synthesis inhibition $24 \mathrm{~h}$ after training does not depend on the US duration. On day 1, animals were subjected to three CS-US pairings (A1-A3) with a short ( $2 \mathrm{~s}$, circles) or long ( $10 \mathrm{~s}$, triangles) US presentation (acquisition). After $24 \mathrm{~h}$, on day 2, emetine (black symbols) or PBS (gray symbols) was injected. On day 3, memory was tested (retention). Presented are percentages of bees showing the $\mathrm{CR}$ to the $\mathrm{C} S$ at different phases of the experiment. Arrow, Time of injection. Number of animals: long-Eme, $n=72$; long-PBS, $n=77$; short-Eme, $n=67$; short-PBS, $n=74$.

susceptible to protein synthesis inhibitors $24 \mathrm{~h}$ after acquisition with the new conditioning protocol.

Two groups of bees were trained on day 1 with three CS-US pairings, either with a $2 \mathrm{~s}$ (the short group) or a $10 \mathrm{~s}$ US presentation (the long group). On the next day both groups were divided into two subgroups and received either an injection (10 $\mathrm{mm}$ ) of the protein synthesis inhibitor emetine (short-Eme, longEme) or saline (short-PBS, long-PBS). Memory retention was tested on day 3 (Fig. 1).

The conditioned responses (CRs) of the short and the long groups were not significantly different in the second and third acquisition trials $\left[G_{\mathrm{A} 2}=3.81\right.$, not significant (NS), $G_{\mathrm{A} 3}=0.20$, $\mathrm{NS}, \mathrm{df}=3)$. Hence, the length of the US presentation does not influence performance during acquisition.

Furthermore, no significant differences between the groups $\left(G_{\text {Test_All }}=1.40, \mathrm{NS}, \mathrm{df}=3\right)$ were found in the retention test on day 3 . We conclude that the formation of the CS-US memory cannot be disturbed by protein synthesis inhibitors applied $24 \mathrm{~h}$ after training, regardless of the duration of the US. This finding allows us to study consolidation processes that result from retrieving the CS-US memory $24 \mathrm{~h}$ after acquisition.

\section{Sensitivity of memory formation to protein synthesis inhibition after extinction with one CS-only trial does not depend on US duration during training}

We demonstrated above that protein synthesis inhibitors applied around the time of memory retrieval $1 \mathrm{~d}$ after training do not interfere with the consolidation process of the CS-US memory. Next, we tested whether the duration of the US presentation during acquisition has an impact on the memory formation after memory retrieval. On day 1, two groups of animals were trained either with a short US presentation of $2 \mathrm{~s}$ (short group) or a long 


\section{Extinction trial}

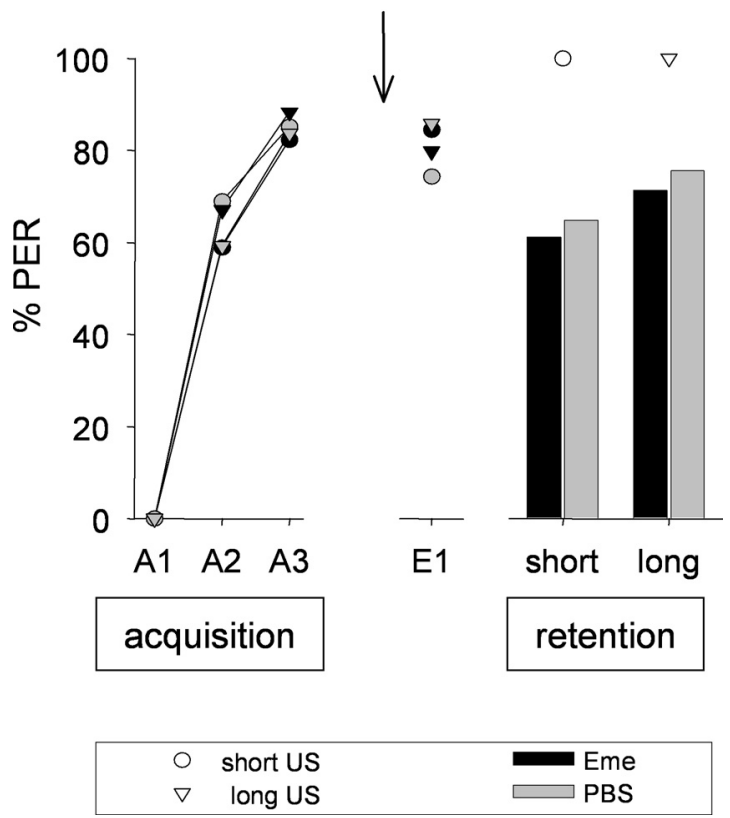

Figure 2. Sensitivity of memory formation to protein synthesis inhibition after extinction with one CS-only trial does not depend on the US duration during training. On day 1, animals were subjected to three $\mathrm{CS}-\mathrm{US}$ pairings (A1-A3) with a short ( $2 \mathrm{~s}$, circles) or long (10 s, triangles) US presentation (acquisition). After $24 \mathrm{~h}$, on day 2, emetine (black symbols) or PBS (gray symbols) was injected 30 min before one (S-only trial (E1). On day 3, memory was tested (retention). Presented are percentages of bees showing the $C R$ to the $C S$ at different phases of the experiment. Arrow, Time of injection. Number of animals: long-Eme, $n=94$; long-PBS, $n=98$; short-Eme, $n=74$; short-PBS, $n=90$.

US presentation of $10 \mathrm{~s}$ (long group). On day 2, both groups were divided into two subgroups and were systemically injected with $10 \mathrm{~mm}$ emetine (short-Eme, long-Eme) or saline (short-PBS, long-PBS); 30 min later, all animals were subjected to memory retrieval with one CS-only presentation. On day 3 , memory retention of all groups was tested (Fig. 2).

On day 1, during the course of acquisition, the CRs were not significantly different in the second and the third trials between groups $\left(G_{\mathrm{A} 2}=0.01, \mathrm{NS} ; G_{\mathrm{A} 3}=0.40, \mathrm{NS}, \mathrm{df}=3\right)$.

On day 2, the first memory retrieval with one CS-only trial yielded no differences in CRs among the four retrieved groups $\left(G_{\text {All }}=4.27, \mathrm{NS}, \mathrm{df}=3\right)$. Also, CRs in the retention test on day 3 were not significantly different for all groups $\left(G_{\mathrm{All}}=5.32\right.$, $\mathrm{NS}, \mathrm{df}=3$ ).

In comparing CRs during retrieval on day 2 with the CRs at the final retention test, a McNemar test designated them as nonsignificantly different for both long groups (long-Eme, long-PBS) and for the saline-injected short group (short-PBS) (McNemar: $\chi_{\mathrm{L} \text {-Eme }}^{2}=$ $1.88, \mathrm{NS} ; \chi_{\mathrm{L}-\mathrm{PBS}}^{2}=3.76, \mathrm{NS} ; \chi_{\text {S-PBS }}^{2}=2.12$, N.S, $\mathrm{df}=1$ ). Thus, no significant extinction did take place in the short or in either of the long groups from day 2 to day 3 . Nevertheless, in the emetinetreated short group (short-Eme), the decrease in CR from day 2 to the final retention test is significant (McNemar: $\chi^{2}{ }_{\text {S-Eme }}=$ $13.79, p<0.001, \mathrm{df}=1)$. This might suggest a weak reconsolidation phenomenon. Nevertheless, it should be noted that the criterion for the reconsolidation phenomenon, a significant difference in CRs at the last retention test between the groups treated with and without protein synthesis inhibitor (Nader, 2003), is not fulfilled here $\left(G_{\text {short }}=0.25, \mathrm{NS}, \mathrm{df}=1\right)$.

\section{Extinction trials}

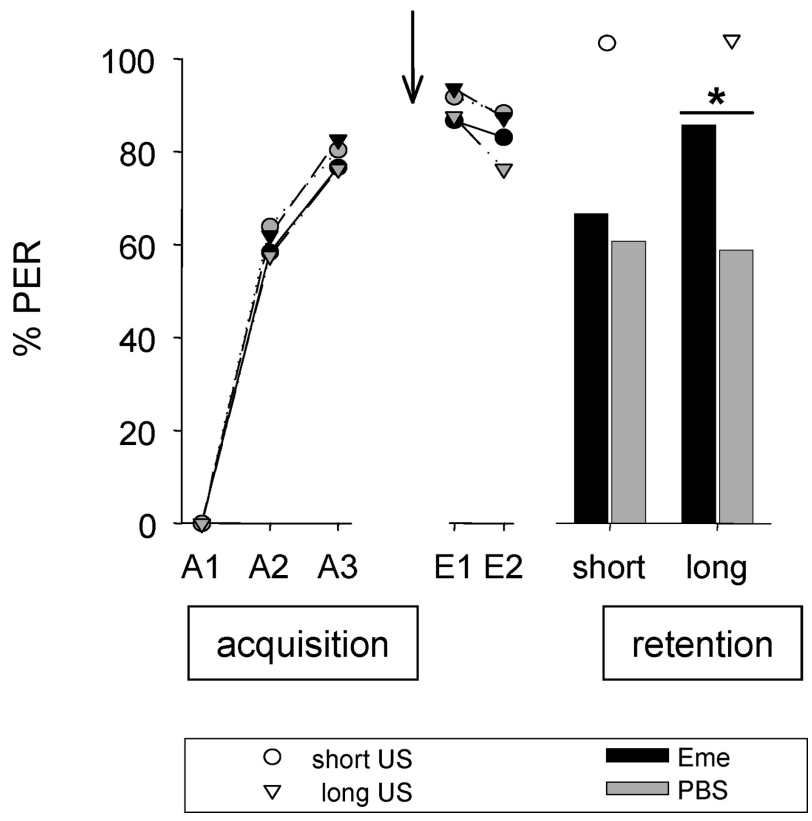

Figure 3. Formation of an extinction memory after extinction with two CS-only trials is sensitive to protein synthesis inhibition when the animals are trained with a long US duration. On day 1 , animals were subjected to three CS-US pairings (A1-A3) with a short ( $2 \mathrm{~s}$, circles) or long (10 s, triangles) US presentation (acquisition). After $24 \mathrm{~h}$, on day 2, emetine (black symbols) or PBS (gray symbols) was injected 30 min before two CS-only trials (E1, E2). On day 3, memory was tested (retention). Presented are percentages of bees showing the $\mathrm{CR}$ to the $\mathrm{CS}$ at different phases of the experiment. Asterisk indicates significant differences $(p<0.05)$. Arrow, Time of injection. Number of animals: long-Eme, $n=86$; long-PBS, $n=72$; short-Eme, $n=75$; short-PBS, $n=89$

Formation of an extinction memory is sensitive to protein synthesis inhibition only when the animals were trained with a long US duration

Next we tested whether the US duration affects retrievaldependent consolidation after two CS-only trials. In a previous study it was found that two CS-only trials applied $24 \mathrm{~h}$ after acquisition result in the formation of a protein synthesisdependent extinction memory (Stollhoff et al., 2005).

Again, honeybees were trained with the short or long conditioning protocol on day 1 . On day 2, injections of emetine or saline were applied (short-PBS, short-Eme, long-PBS or longEme) and 30 min afterward, all animals received two CS-only trials with a $10 \mathrm{~min}$ intertrial interval. On day 3 , memory retention of all groups was tested (Fig. 3).

There is no significant difference in CRs during the course of acquisition $\left(G_{\mathrm{A} 2}=0.01, \mathrm{NS} ; G_{\mathrm{A} 3}=0.11, \mathrm{NS}, \mathrm{df}=3\right)$. On day 2, animals were subjected to two CS-only trials (E1, E2). The CRs of all groups were not significantly different in the first and the second retrieval trials $\left(G_{\mathrm{E} 1}=2.47, \mathrm{NS} ; G_{\mathrm{E} 2}=\right.$ 3.95, NS, $\mathrm{df}=3$ ). In both saline-treated groups (long-PBS, short-PBS) the CRs decreased significantly from E2 to the retention test on day 3 (McNemar test, $\chi_{\text {S-PBS }}^{2}=10.23, p<$ $\left.0.05 ; \mathrm{df}=1 ; \chi_{\text {L-PBS }}^{2}=5.63, p<0.05, \mathrm{df}=1\right)$. Thus, after two CS-only trials, extinction took place from day 2 to day 3 in the short and the long groups.

By comparing the CRs of the long group at the retention test at day 3, a $G$ test revealed a significant difference $\left(G_{\text {long }}=4.54, p<\right.$ $0.05, \mathrm{df}=1)$, but not between both short groups $\left(G_{\text {short }}=0.47\right.$, $\mathrm{NS}, \mathrm{df}=1$ ). Thus, a protein synthesis-dependent formation of an extinction memory is only visible in the long group. 


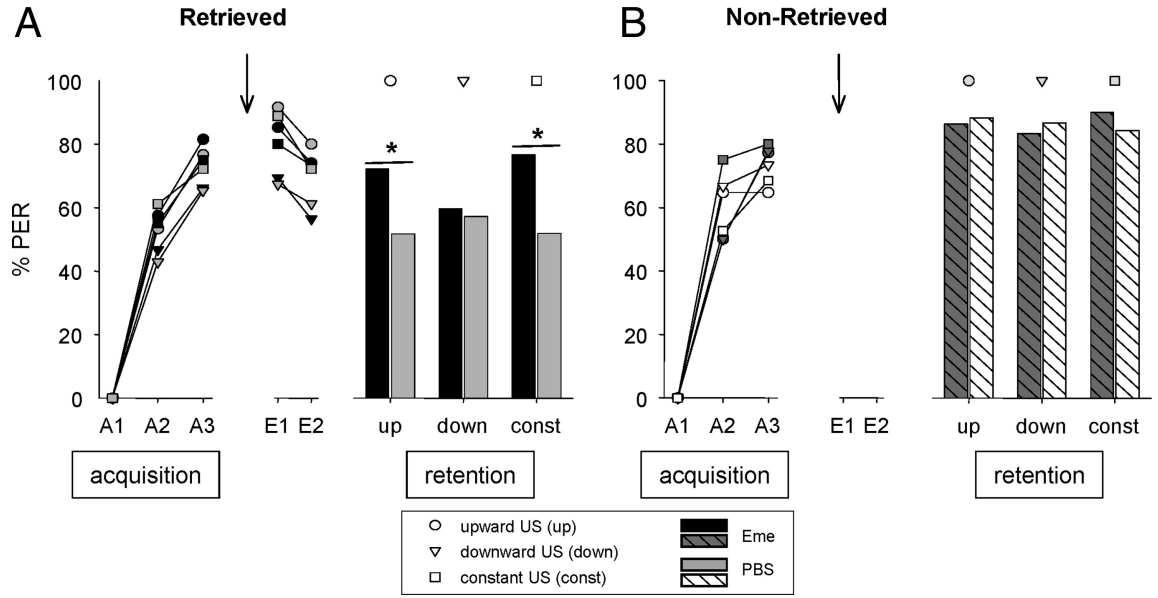

Figure 4. Differences in the consolidation of an extinction memory are not attributable to differences in satiation level. $\boldsymbol{A}$, Retrieved. On day 1, animals were subjected to three CS-US pairings (A1-A3) with an increasing duration (upward $2 \mathrm{~s}, 6 \mathrm{~s}, 10 \mathrm{~s}$; circles), a constant duration (constant $6 \mathrm{~s}$; squares), or a decreasing duration (downward 10s, $6 \mathrm{~s}, 2 \mathrm{~s}$; triangles) of US presentations during training (acquisition). After $24 \mathrm{~h}$, on day 2, emetine (black symbols) or PBS (gray symbols) was injected 30 min before two CS-only trials (E1, E2). On day 3, memory was tested (retention). Number of animals: up-Eme_R, $n=54$; up-PBS_R, $n=60$; const-Eme_R, $n=60$; const-PBS_R, $n=54$; down-Eme_R, $n=62$; down-PBS_R: $n=49$. $\boldsymbol{B}$, Non-retrieved. On day 1, animals were subjected to three $C S-U S$ pairings (A1-A3) with an increasing duration (upward $2 \mathrm{~s}, 6 \mathrm{~s}, 10 \mathrm{~s}$; circles), a constant duration (constant $6 \mathrm{~s}$; squares), or a decreasing duration (downward $10 \mathrm{~s}, 6 \mathrm{~s}, 2 \mathrm{~s}$; triangles) of US presentations during training (acquisition). After $24 \mathrm{~h}$, on day 2, emetine (black symbols) or PBS (gray symbols) was injected. On day 3, memory was tested (retention). Number of animals: up-Eme, $n=22$; up-PBS, $n=17$; const-Eme, $n=20$; const-PBS, $n=19$; down-Eme, $n=18$; down-PBS, $n=15$. Presented are percentages of bees showing the $C R$ to the $C S$ at different phases of the experiment. Asterisk indicates significant differences $(p<0.05)$. Arrow, Time of injection.

Accordingly, the US duration during acquisition has an impact on memory consolidation after retrieval with two CS-only trials.

\section{Differences in the consolidation of an extinction memory are not attributable to differences in the satiation level}

We demonstrated above that the consolidation of an extinction memory depends on the US duration during acquisition. Compared with the short group (2s), bees in the long group (10 s) were allowed to lick the sucrose solution for an additional $8 \mathrm{~s}$; therefore, they most likely received a larger amount of sucrose than animals in the short group. Thus, the observed phenomenon might be the result of the degree of satiation, which differs between animals in the short and in the long groups. Indeed, the satiation level in honeybees is critical for the protein synthesisdependent formation of an olfactory memory: bees fed $4 \mathrm{~h}$ before conditioning show impaired acquisition performance and a lower response probability during the subsequent retention test compared with bees that were fed $18 \mathrm{~h}$ before conditioning (Friedrich et al., 2004). In the following experiment, we wanted to rule out this possibility. We designed an experiment such that three experimental groups had comparable satiation levels after the conditioning phase, but differed in the duration of the US presentation from trial to trial: the first group was trained with increasing US durations, from $2 \mathrm{~s}$, to $6 \mathrm{~s}$, to $10 \mathrm{~s}$ (upward); the second group was trained with decreasing US durations, from $10 \mathrm{~s}$, to $6 \mathrm{~s}$, to $2 \mathrm{~s}$ (downward). Accordingly, the first and the last trial for each group resembled the US duration of the long and the short group, respectively. In addition, a third group was trained with a constant US duration of $6 \mathrm{~s}$ in all three trials (constant). Accordingly, all experimental groups experienced the same mean US duration ( $6 \mathrm{~s})$. The constant group was designed as a control group for the induction of a protein synthesis-dependent extinction memory. A protein synthesis-dependent extinction memory is formed after retrieval of a memory for a CS paired with a $4 \mathrm{~s}$ US
(Stollhoff et al., 2005) or with a $10 \mathrm{~s}$ US, but not after retrieval of a memory for a CS paired with a $2 \mathrm{~s}$ US. We thus supposed that a protein synthesis-dependent extinction memory is also formed after retrieving a memory for a CS paired with a 6 s US. Our hypothesis was as follows. If the satiation level is the critical factor, all three groups should show a protein synthesis-dependent extinction memory.

The three groups were trained in parallel according to the following scheme. On day 1 the three groups were trained with the variation in US durations during acquisition (const, up, down) as described above. On day 2 each of the three groups was divided into two subgroups that were systemically injected with $10 \mathrm{~mm}$ emetine or saline (PBS); 30 min later the subgroups were divided again into two groups, one of which was subjected to memory retrieval with two CS-only presentations (Eme: up-Eme_R, downEme_R, const-Eme_R; PBS: up-PBS_R, down-PBS_R, const-PBS_R). The other one was left as a nonretrieved control group (Eme: up-Eme, down-Eme, constEme; PBS: up-PBS, down-PBS, constPBS). On day 3 , memory retention of all groups was tested again (Fig. $4 A, B$ ).

On day 1 , during conditioning, a $G$ test revealed no significant differences for the second and the third acquisition trial over all three groups (up, down, constant) in the retrieved $\left(G_{\mathrm{A} 2}=4.92\right.$, $\mathrm{NS}, \mathrm{df}=5 ; G_{\mathrm{A} 3}=5.50 ; \mathrm{NS}, \mathrm{df}=5$ ) or in the nonretrieved groups $\left(G_{\mathrm{A} 2}=4.48, \mathrm{NS}, \mathrm{df}=5 ; G_{\mathrm{A} 3}=1.67 ; \mathrm{NS}, \mathrm{df}=5\right)$.

On day 2, comparison of all retrieved groups revealed significant differences in CRs in the first (E1) but not in the second (E2) retrieval trial $\left(G_{\mathrm{E} 1}=18.46, p<0.01, \mathrm{df}=5, G_{\mathrm{E} 2}=10.74, p=\right.$ $0.057, \mathrm{df}=5)$. The tests revealed significant differences in the first retrieval trial $(\mathrm{E} 1)$ among all saline-treated groups $\left(G_{\mathrm{PBS} \_\mathrm{R}}=\right.$ $12.35, p<0.01, \mathrm{df}=2$ ) but not among all emetine-treated groups $\left(G_{\text {Eme_R }}=4.41, \mathrm{NS}, \mathrm{df}=2\right)$. The CR of the down-PBS group is significantly lower than the response of the two others $\left(G_{\text {up-PBS_down-PBS }}=10.51, p<0.01 ; G_{\text {const-PBS_down-PBS }}=7.27\right.$, $p<0.01, \mathrm{df}=2)$.

On day 3 , memory retrieval revealed significant differences in CRs between the retrieved groups $\left(G_{\text {retrieved }}=13.94, p<\right.$ $0.05, \mathrm{df}=5$ ) (Fig. $4 A$ ) but not between the nonretrieved groups $\left(G_{\text {nonretrieved }}=0.50, \mathrm{NS}, \mathrm{df}=5\right)$ (Fig. $\left.4 B\right)$. In two groups, the retrieved upward group and the retrieved constant group, the CR was higher in emetine-treated animals than in saline-treated animals. These differences were found to be significant $\left(G_{\text {up_R }}=\right.$ $\left.5.13, p<0.05, \mathrm{df}=1, G_{\text {const_R }}=7.76, p<0.01, \mathrm{df}=1\right)$, whereas CRs of the downward group were similar for the emetine- and saline-treated animals $\left(G_{\text {down_R }}=0.072, \mathrm{NS}, \mathrm{df}=1\right)($ Fig. $4 A)$. The comparison of the second retrieval trial on day 2 and the retention test on day 3 revealed a decreased CR on day 3 in the upward group and the constant group, and this difference was significant $\left(\mathrm{McNemar}\right.$ test: $\chi_{\text {up-Eme_R }}^{2}=2.77, \mathrm{NS} ; \chi_{\text {up-PBS_R }}^{2}=$ $17.63, p<0.001 ; \chi_{\text {const-Eme_R }}^{2}=0.53$, NS; $\chi_{\text {const-PBS_R }}^{2}=15.04$, $p<0.001, \mathrm{df}=1)$. Accordingly, a protein synthesis-dependent extinction memory was formed $24 \mathrm{~h}$ after retrieval in the upward and the constant groups. In contrast, in the downward group, no signif- 
icant difference was found between days 2 and $3\left(\chi^{2}\right.$ down-Eme_R $=$ 1.39 , NS, $\left.\chi_{\text {down-PBS_R }}^{2}=1.07, \mathrm{NS}, \mathrm{df}=1\right)($ Fig. $4 A)$. We conclude that in this group, extinction did not take place and an extinction memory was not consolidated.

We predicted that on day 3, all three experimental groups would have had the same memory retention in the retrieved saline groups and in the retrieved emetine groups, respectively, if the level of satiation had been the critical factor for the consolidation of retrieval-dependent memories to occur. We did not observe such dependence and, therefore, conclude that it is not the level of satiation during conditioning that is critical for the consolidation of an extinction memory.

\section{Discussion}

Here, we aim toward elucidating the role of US magnitude during conditioning on memory consolidation after retrieval. To this end, we varied the US duration and tested the impact on protein synthesis-dependent memory formation after one and two retrieval trials. We show that one retrieval trial does not induce any consolidation process and that the US duration is critical for the consolidation of an extinction memory when memory is retrieved with two retrieval trials. We rule out the possibility that it is the level of satiation that is responsible for these differences.

\section{How does the US duration during training affect memory consolidation after retrieval?}

Using two different US durations for conditioning, $2 \mathrm{~s}$ (short group) and $10 \mathrm{~s}$ (long group), revealed that the US duration is critical for the consolidation of an extinction memory. How can this result be conceptualized? In our experiments, a difference between the US that has been presented during training and the absence of the US during retrieval exists, which is thought to be the cause for the observed extinction learning (Bouton, 2004). Regarding the US duration, the absolute value of this difference is smaller in the short group than in the long group. We interpret this as a difference in magnitude of the mismatch between what has been experienced before and the actual experienced US. Accordingly, we conclude that it is the magnitude of this mismatch that drives memory consolidation.

\section{The magnitude of the mismatch resembles the prediction error}

The mismatch between what has been experienced, before, and the actual experienced rewards is conceptualized as an error in the prediction of outcome (Schultz and Dickinson, 2000). In vertebrates, dopaminergic neurons carry a signal that resembles a prediction error (Schultz, 2006). In honeybees, the VUMmxl neuron serves an appetitive-reinforcing function in olfactory PER conditioning. It initially fires when the bee is exposed to a sucrose stimulus, and its activity is a US that is equally effective as sucrose (Hammer, 1993). After classical conditioning, it increases its activity if exposed to the trained odor (Hammer, 1993). VUMmx1 is activated more by odors that predict reward than by odors that do not predict reward (Hammer, 1993). Thus, neuronal correlates of the prediction error concept exist in both vertebrates and honeybees. It is conceivable that the respective neurons are involved in driving consolidation after memory retrieval.

\section{Is it all about associative strength?}

Rescorla and Wagner (1972) suggested that the strength of the association between a CS and a US (or a no-US) increases as long as a mismatch between the predicted and the experienced US exists. When the mismatch is nil and the US is fully predicted by the CS, the associative strength no longer increases (Schultz and Dickinson, 2000). Varying the magnitude of US during PER conditioning should lead to differences in the strength of the CS-US association during conditioning. Rescorla and Wagner (1972) propose that the associative strength, which is a concept rather than a measurable value, maps onto the rate of CR. This does not hold true for our study, suggesting that the different US durations during conditioning do not change the associative strength of the CS. However, we suggest that the dichotomous data generated here (extension of the proboscis: yes or no) are not an adequate measure to map the CS associative strength to its behavior, and it might well be that quantifiable responses like the activity of the proboscis-extending muscle M17 (Rehder, 1987; Smith and Menzel, 1989) or the reaction time of PER (Gil et al., 2008) reveal the proposed differences in associative strength. This is supported by findings in free-flying bees that were trained to artificial flowers. Time assigned to flower inspection revealed effects of different reward magnitudes during training that were not visible when choice-based measures, only, were evaluated (Gil et al., 2007).

Results on the effect of the US duration on learning behavior are inconsistent in general. Some studies demonstrate that the US duration affects learning behavior (Morris and Bouton, 2006), but others do not (Wegner and Zeaman, 1958; Ashton et al., 1969). The reason for this inconsistency is unclear, and it seems that at least the interrelationship between US duration and learning behavior is not yet understood. Interestingly, Rescorla and Wagner (1972), whose influential model describes the change of the associative strength of the CS as a result of a conditioning trial, underlined that "mapping of the associative strength would be peculiar to each experimental situation and depend on a large number of performance variables." Thus, the absence of a correlation between the US duration and the conditioned response does not necessarily demonstrate that the US duration has no impact on the association between the CS and the US.

\section{A protein synthesis-independent LTM?}

Two types of extinction memories are formed after memory retrieval with two CS-only trials, depending on the duration of the US: one memory can be inhibited by $10 \mathrm{~mm}$ protein synthesis inhibitor, and one memory that cannot be inhibited by this amount of inhibitor. It is unclear whether the latter memory has been formed independently of protein synthesis and, therefore, cannot be inhibited, or whether the dose of inhibitor used in this study is not sufficient. Indeed, in a previous study we demonstrate inhibition of retrieval-induced consolidation only with a $20 \mathrm{~mm}$ dose of protein synthesis inhibitor (Stollhoff et al., 2008). However, this previous study examined reconsolidation after one CS-only trial, which affects behavior only $4 \mathrm{~d}$ after memory retrieval. Nevertheless, it might well be that the extinction memory after conditioning with a short US can only be inhibited by a higher dose of protein synthesis inhibitor. A reason for this could be a stronger memory trace formed after a short than after a long US duration, which is not susceptible to the amount of inhibitor we used in this study. We cannot rule out this possibility. Nevertheless, our study reveals that the US duration is a critical factor leading to differences in the formation of a protein synthesis-dependent extinction memory, and hence its consolidation. 


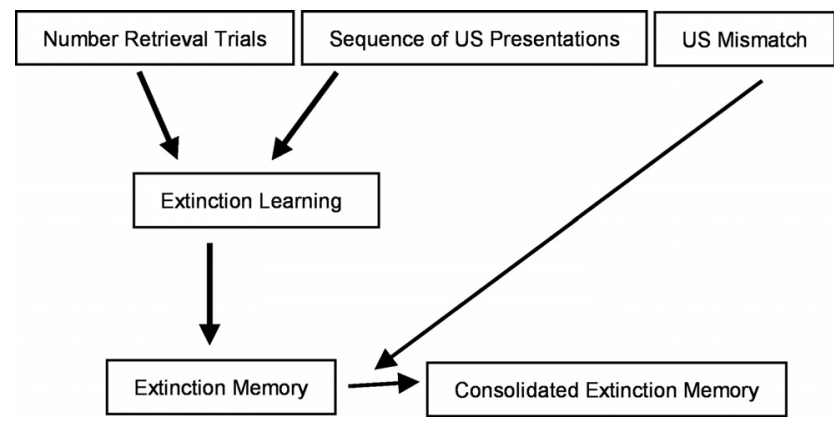

Figure 5. At least two independent parameters influence extinction learning and the consolidation of an extinction memory. Model of how extinction learning and the formation of an extinction memory depend on three independent parameters. The sequence of US durations (constant, increasing, decreasing) and the number of retrieval trials are critical for extinction learning. The US duration, resulting in a difference in magnitude of the mismatch (mismatch US) between the experienced US during conditioning and the absence of the US during retrieval is critical for consolidation of an extinction memory.

\section{Long-term extinction memories with different biochemical identities}

Several authors critically discuss the requirement of protein synthesis for the formation of long-term extinction memories (Lattal et al., 2006). Here, we demonstrated that long-term extinction memories are formed depending on protein synthesis, but that the US magnitude is one critical parameter for this protein synthesis-dependent memory formation. Accordingly, after extinction learning, long-term memories can be formed with different biochemical identities, i.e., with or without protein synthesis, comparable to memory formation after acquisition, as it has been demonstrated in Drosophila melanogaster (Tully et al., 1994; Isabel et al., 2004). There, two $24 \mathrm{~h}$ memories are described that are mutually exclusive: the protein synthesis-dependent LTM and the protein synthesis-independent anesthesia-resistant memory (ARM) (Isabel et al., 2004). Their formation depends on the way the animals are trained. The authors propose that ARM prevents LTM formation after a single training trial. LTM can be formed only after spaced training, when ARM is erased. Accordingly, only a CS with a high predictive value gained after multiple CS-US pairings is stored in LTM. In contrast, a CS-US pairing encountered only once for a short time (single trial) or for a longer time (massed training) would generate a semistabilized memory (ARM) that does not involve a heavy cascade of gene expression (Isabel et al., 2004).

\section{Independent parameters influence extinction learning and consolidation of an extinction memory}

In a previous study we demonstrate that the number of retrieval trials influences extinction (Stollhoff et al., 2005). This study reveals that this influence is independent of the US duration during training. Extinction and formation of an extinction memory are not observable after one retrieval trial, but after two retrieval trials. In contrast, the US duration is crucial for the formation of a protein synthesis-dependent memory after two retrieval trials. Animals that were presented with a constant US duration of 10 or $6 \mathrm{~s}$ form a protein synthesis-dependent extinction memory, whereas animals that received a US presentation of $2 \mathrm{~s}$ did not. Accordingly, a threshold exists for the US duration: only when it exceeds $2 \mathrm{~s}$ formation of an extinction memory is protein synthesis dependent. Hence, at least two parameters play a role: the number of retrieval trials controlling extinction learning and the formation of an extinction memory, per se, and the US duration driving the protein synthesis-dependent formation of the extinction memory (Fig. 5). Nevertheless, it should be noted that extinction was not observable in animals that received decreasing US durations during training, although the US duration at the last trial lasted for $2 \mathrm{~s}$ such as the US at every trial in the short group, where extinction took place. Thus, the sequence of US presentations might be a further parameter that influences the occurrence of extinction and the formation of an extinction memory, suggesting that the animal's expectation of the reward duration plays a role in controlling extinction learning (Gil et al., 2008).

Here, we show for the first time that the protein synthesis dependency of long-term memory formation depends on the US duration during training. We demonstrate that memory formation about new experiences cannot be regarded as an isolated process, because the animal's previous experience is one parameter that determines protein synthesis-dependent memory formation and, hence, memory consolidation.

\section{References}

Ashton AB, Bitgood SC, Moore JW (1969) Auditory differential conditioning of the rabbit nictitating membrane response: III. Effect of US shock intensity and duration. Psychon Sci 15:127-128.

Bouton ME (2004) Context and behavioural processes in extinction. Learn Mem 11:485-494.

Dudai Y (2002) Memory from A to Z. Keywords, concepts and beyond. Oxford: Oxford UP.

Dudai Y (2004) The neurobiology of consolidations, or, how stable is the engram? Annu Rev Psychol 55:51-86.

Eisenberg M, Kobilo T, Berman DE, Dudai Y (2003) Stability of retrieved memory: inverse correlation with trace dominance. Science 301:1102-1104.

Friedrich A, Thomas U, Müller U (2004) Learning at different satiation levels reveals parallel functions for the cAMP-protein kinase A cascade in formation of long-term memory. J Neurosci 24:4460-4468.

Gil M, De Marco RJ, Menzel R (2007) Learning reward expectations in honeybees. Learn Mem 14:491-496.

Gil M, Menzel R, De Marco RJ (2008) Does an insect's unconditioned response to sucrose reveal expectations of reward? PLoS ONE 3:e2810.

Hammer M (1993) An identified neuron mediates the unconditioned stimulus in associative olfactory learning in honeybees. Nature 366:59-63.

Isabel G, Pascual A, Preat T (2004) Exclusive consolidated memory phases in Drosophila. Science 304:1024-1027.

Lagasse F, Devaud JM, Mery F (2009) A switch from cycloheximideresistant consolidated memory to cycloheximide-sensitive reconsolidation and extinction in Drosophila. J Neurosci 29:2225-2260.

Lattal KM, Radulovic J, Lukowiak K (2006) Extinction: does it or doesn't it? The requirement of altered gene activity and new protein synthesis. Biol Psychiatry 60:344-351.

Menzel R (1968) Das Gedächtnis der Honigbiene für Spektralfarben. Z Vgl Physiol 60:82-102.

Menzel R (1999) Memory dynamics in the honeybee. J Comp Physiol A 185:323-340.

Morris RW, Bouton ME (2006) Effect of unconditioned stimulus magnitude on the emergence of conditioned responding. J Exp Psychol Anim Behav Process 32:371-385.

Nader K (2003) Memory traces unbound. Trends Neurosci 26:65-72.

Pedreira ME, Maldonado H (2003) Protein synthesis subserves reconsolidation or extinction depending on reminder duration. Neuron 38:863-869.

Power AE, Berlau DJ, McGaugh JL, Steward O (2006) Anisomycin infused into the hippocampus fails to block "reconsolidation" but impairs extinction: the role of re-exposure duration. Learn Mem 13:27-34.

Quirk GJ, Mueller D (2008) Neural mechanisms of extinction learning and retrieval. Neuropsychopharmacology 33:56-72.

Rehder V (1987) Quantification of the honeybees proboscis reflex by electromyographic recordings. J Insect Physiol 33:501-507.

Rescorla RA, Wagner AR (1972) A theory of classical conditioning: variations in the effectiveness of reinforcement and non-reinforcement. In: 
Classical conditioning II: current research and theory (Black P, ed), pp 64-99. New York: Appleton-Century-Crofts.

Sara SJ (2000) Retrieval and reconsolidation: toward a neurobiology of remembering. Learn Mem 7:73-84.

Schultz W (2006) Behavioral theories and the neurophysiology of reward. Annu Rev Psychol 57:87-115.

Schultz W, Dickinson A (2000) Neuronal coding of prediction errors. Annu Rev Neurosci 23:473-500.

Smith BH, Menzel R (1989) The use of electromyogram recordings to quantify odorant discrimination in the honey bee, Apis mellifera. J Insect Physiol 35:369-375.

Stollhoff N, Menzel R, Eisenhardt D (2005) Spontaneous recovery from extinction depends on the reconsolidation of the acquisition memory in an appetitive learning paradigm in the honeybee (Apis mellifera). J Neurosci 25:4485-4492.

Stollhoff N, Menzel R, Eisenhardt D (2008) One retrieval trial induces reconsolidation in an appetitive learning paradigm in honeybees (Apis mellifera). Neurobiol Learn Mem 89:419-425.

Suzuki A, Josselyn SA, Frankland PW, Masushige S, Silva AJ, Kida S (2004) Memory reconsolidation and extinction have distinct temporal and biochemical signatures. J Neurosci 24:4787-4795.

Tully T, Preat T, Boynton SC, Del Vecchio M (1994) Genetic dissection of consolidated memory in Drosophila. Cell 79:35-47.

Wegner N, Zeaman D (1958) The strength of cardiac CRs with varying unconditioned stimulus durations. Psychol Rev 65:238-241.

Zar JH (1984) Biostatistical analysis. Englewood Cliffs, NJ: Prentice Hall. 